\title{
Cirurgia conservadora de próteses aórtica e mitral na endocardite infecciosa
}

\author{
Kanim Kalil KASSAB*, José Antônio Garcia MENEGOLI*, Vera Lúcia A. M. PICARDI*, Marcos Cesar \\ V. de ALMEIDA*, Emil SABINO*, Edgard SAN JUAN*, Ricardo Gomes CAMACHO*, \\ César Morioki OGIDO*, Enoch Brandão de Souza MEIRA*
}

RBCCV 44205-532

\begin{abstract}
Kassab K K, Menegoli J A G, Picardi V L A M, Almeida M C V, Sabino E, San Juan E, Camacho R G, Ogido C M, Meira E B S - Cirurgia conservadora de próteses aórtica e mitral na endocardite infecciosa. Rev Bras Cir Cardiovasc 2001; 16(1): 62-5.

RESUMO: A endocardite infecciosa (El) acometendo próteses valvares é uma complicação freqüente, sendo tratada geralmente com cirurgia, devido ao seu difícil controle clínico e má resposta à antibioticoterapia. Este relato descreve o caso de uma paciente com El, acometendo simultaneamente as biopróteses aórtica (Ao) e mitral (Mi) após vinte e quatro meses de cirurgia de implantes valvares, submetida a tratamento cirúrgico conservador, e com resultado favorável. Discutem-se as vantagens deste procedimento em situações específicas.
\end{abstract}

DESCRITORES: Endocardite bacteriana, cirurgia. Implante de prótese de valva, efeitos adversos. Aorta, cirurgia. Valva mitral, cirurgia. Valva aórtica, cirurgia.

\section{INTRODUÇÃO}

A El em próteses valvares é uma complicação de alta morbimortalidade, não apresentando, em geral, boa resposta à antibioticoterapia, sendo tratada classicamente com cirurgia de substituição das próteses (1). Os primeiros casos de tratamento cirúrgico de El valvar datam da déca- da de $1960{ }^{(2)}$, em que era relatada a possibilidade de preservação das valvas (3-5), principalmente quando acometia um pequeno segmento das mesmas $(6,7)$. Este relato descreve o caso de uma paciente com acometimento de biopróteses Ao e Mi que evoluiu satisfatoriamente após a realização de vegetectomia em ambas as próteses.

\footnotetext{
Trabalho realizado no Hospital Servidor Público Estadual de São Paulo - "Francisco Morato de Oliveira". São Paulo, SP, Brasil.

* Do Hospital Servidor Público Estadual de São Paulo - "Francisco Morato de Oliveira".

Recebido para publicação em novembro de 2000.

Endereço para correspondência: Kanim Kalil Kassab. Rua Vergueiro, 1247 - Apto 72 . São Paulo, SP, Brasil. CEP 01504-001. Celular. (11) 9302.3037 e-mail:kanim@ig.com.br
} 
Kassab K K, Menegoli J A G, Picardi V L A M, Almeida M C V, Sabino E, San Juan E, Camacho R G, Ogido C M, Meira E B S - Cirurgia conservadora de próteses aórtica e mitral na endocardite infecciosa. Rev Bras Cir Cardiovasc 2001; 16(1): 62-5.

\section{RELATO DO CASO}

V.A .M. S, 40 anos, feminina, branca, com história de febre reumática desde os 8 anos de idade, internada em outubro de 1996, com quadro de dor no hemitórax direito e tosse com escarro hemoptóico. O exame físico à admissão mostrava quadro hemodinâmico estável com ritmo cardíaco regular, sopros sistólico ${ }^{+++/ 6+}$, diastólico ${ }^{+/ 6+}$ no foco Ao e sistólico ${ }^{++/ 6+}$ no foco Mi. A hipótese de dupla lesão Ao e insuficiência Mi importante foi confirmada pelo ecocardiograma transtorácico. Foi submetida a tratamento cirúrgico, com substituições valvares $\mathrm{Mi}$ e Ao por biopróteses de pericárdio bovino números 25 e $21 \mathrm{~mm}$, respectivamente, obtendo alta hospitalar no 8o dia de pós-operatório.

Após 2 anos sem acompanhamento clínico, retornou com quadro de febre havia uma semana, anorexia e queda do estado geral. O exame físico revelou sopros sistólico ${ }^{++/ 6+}$ no foco Ao e diastólico $++6+$ no foco Mi. A hipótese diagnóstica inicial de El em próteses valvares foi confirmada pelo ecocardiograma, evidenciando-se vegetações de 9x4 $\mathrm{mm}$ na prótese Ao e de $10 \times 5 \mathrm{~mm}$ na Mi (Figuras 1$\mathrm{A}$ e B). A hemocultura não evidenciou crescimento de bactérias e ou fungos. Apesar da antibioticoterapia imediatamente instituída com Vancomicina $1 \mathrm{gr}$ ev / dia e Rifampicina $600 \mathrm{mg}$ ev / dia, a evolução não foi satisfatória, tendo havido importante piora do estado clínico e instabilidade hemodinâmica. Após 20 dias de antibioticoterapia, mantinha-se o quadro séptico, a hemocultura continuava negativa para bactérias e fungos, o ecocardiograma de controle revelava a persistência das vegetações em ambas as próteses, sendo que na bioprótese mitral a vegetação encontrava-se na face atrial do folheto posterior e na bioprótese aórtica, em todos os folhetos, na face aórtica, sendo então indicada a cirurgia. Durante 0 ato operatório, observamos que ambas as próteses estavam normofuncionantes com suas cúspides intactas, sem existir comprometimento periprotético e, devido ao quadro séptico e grave do doente e mal estado geral, optamos por uma cirurgia conservadora, sendo então realizada a vegetectomia em ambas as próteses, com limpeza das mesmas e desinfecção local com Povidine tópico (polivinilpirrolidona-iodo). Após a cirurgia, no 6으 dia pós operatório, foi acrescentada Gentamicina $600 \mathrm{mg}$ ev /dia, devido a presença de Enterobacter $s p$ no material retirado das biopróteses durante a cirurgia e enviados para análise histopatológica. Evoluiu bem no pós-operatório, obtendo alta da UTI no 50 dia. Os exames ecocardiográficos realizados no 70, $18^{\circ}$ e e 35으 dias de pós-operatório evidenciaram próteses $\mathrm{Mi}$ e Ao normofuncionantes e sem vegetações. Nas hemoculturas realizadas no $14^{\circ}$, 22 o e 35 o dias de pós-operatório não houve crescimento bacteriano, sendo assim interrompidos todos
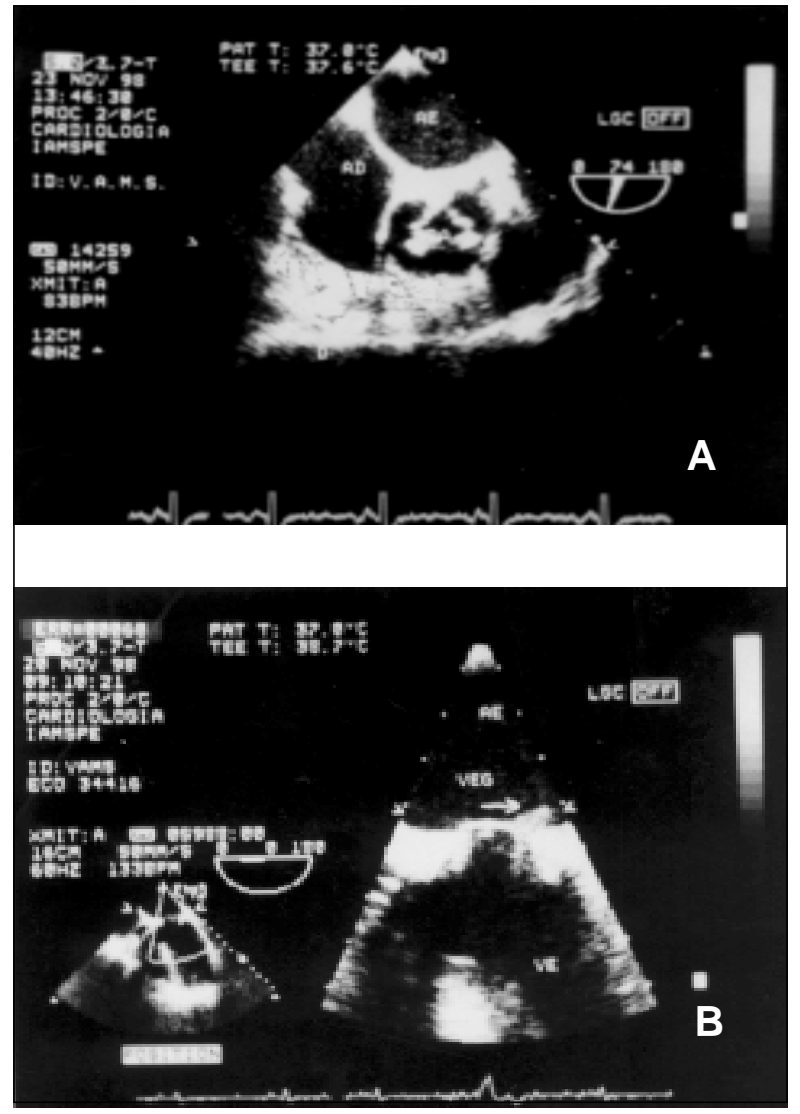

Fig. 1 - Ecocardiograma transtorácico revelando: A) prótese biológica em posição aórtica com vegetações em suas cúspides; B) prótese biológica em posição mitral com grande vegetação em sua face atrial (vide seta).

os antibióticos, obtendo alta no 36 ำ dia de pósoperatório. Decorridos 7 meses após a cirurgia, a paciente encontra-se clinicamente bem, em classe funcional I (NYHA). Todos os ecocardiogramas de controle, inclusive os realizados recentemente, revelaram função normal das próteses e ausência de sinais de infecção (Figuras 2- A e B).

\section{COMENTÁRIOS}

Existem vários estudos mostrando pacientes com El valvar, tratados cirurgicamente com sucesso por meio de plastia e vegetectomia, mas na literatura disponível não foram encontrados relatos que citam o tratamento cirúrgico conservador para a EI em prótese valvar. Estima-se que a incidência de El em prótese $\mathrm{Mi}$ é de $0,5 \%$, e na soma das demais próteses é menor que $1 \%$ (8). SCHUENEMANN et al. ${ }^{(9)}$ mostraram que a incidência de El foi $0,8 \%$ nas próteses biológica e mecânica, e relataram um caso de endocardite tardia em prótese que apresentou 

conservadora de próteses aórtica e mitral na endocardite infecciosa. Rev Bras Cir Cardiovasc 2001; 16(1): 62-5.
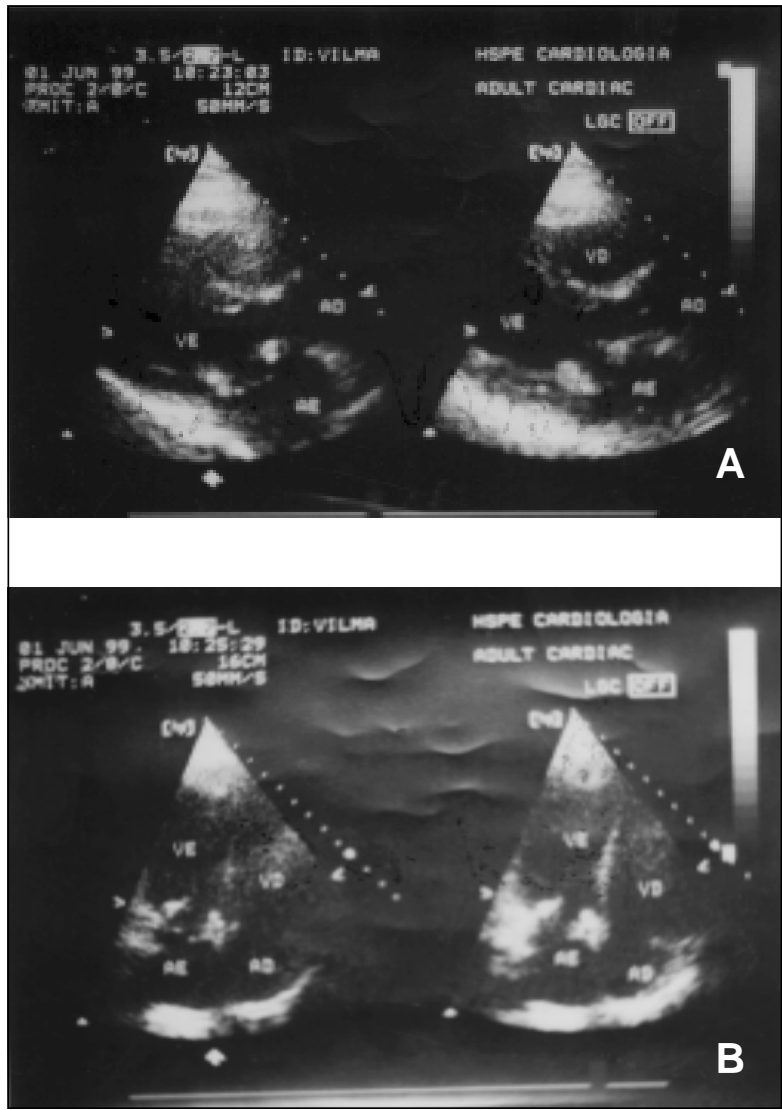

Fig. 2 - Ecocardiograma transtorácico revelando: A) prótese biológica em posição aórtica sem vegetações. B) prótese biológica em posição mitral sem vegetações (vide seta). boa resposta ao tratamento clínico. Entretanto, indicava-se o tratamento cirúrgico o mais precoce possível na presença de instabilidade hemodinâmica severa, abscesso paravalvar, deiscência do anel, episódios embólicos e resistência da infecção à antibioticoterapia (10). Embora clinicamente a El em prótese seja semelhante à endocardite em valva nativa, pacientes portadores de El em prótese apresentam alta morbimortalidade, apesar da antibioticoterapia. EDWARDS et al. (7) relatam que a El é mais freqüente nas próteses mecânicas (74\%) em relação às próteses biológicas (26\%), e que a mortalidade nos primeiros 30 dias de pós-operatório é de $19,9 \%$.

No presente caso, a opção por uma técnica cirúrgica conservadora foi determinada pela gravidade do quadro clínico, já que provavelmente a paciente não suportaria maior tempo de circulação extracorpórea, e ainda porque ambas as próteses apresentavam-se normofuncionantes, com suas cúspides intactas e anéis de implantação, bem como tecidos adjacentes sem qualquer sinal de infecção. Provavelmente não tenha havido crescimento de germes nas hemoculturas devido à antibióticoterapia.

Embora seja um resultado favorável em caso isolado, esta técnica poderá representar uma alternativa na abordagem cirúrgica de alguns casos especiais de endocardite El em prótese valvar. No entanto, será necessária maior experiência com este tipo de procedimento para se avaliar bem o seu real valor.

Kassab K K, Menegoli J A G, Picardi V L A M, Almeida M C V, Sabino E, San Juan E, Camacho R G, Ogido C M, Meira E B S - Conservative surgery for aortic and mitral prosthesis in infective endocarditis. Rev Bras Cir Cardiovasc 2001; 16(1): 62-5.

ABSTRACT: Infective endocarditis is a frequent complication for valvar prosthesis currently treated with surgery, orving to its difficult control and poor response to therapy with antibiotics. Although conservative surgery for infective endocarditis of prosthesis is not a procedure of choice, this report shows a case of infective endocarditis of aortic and mitral prosthesis, after 24 months of implantation, treated by conservative surgery with favorable outcome.

DESCRIPTORS: Endocardites, bacterial, surgery. Heart valve prosthesis implantation, adverse effects. Aorta, surgery. Mitral valve, surgery. Aortic valve, surgery. 


\section{REFERÊNCIAS BIBLIOGRÁFICAS}

1 Manhas D R, Mohri H, Hassel E. Experience with surgical management of primary infective endocarditis: a collected revienv of 139 patients. Am Heart J 1972; 84: 738-47.

2 Kay J H, Bernstein S, Feinstein D-Surgical cure of Candida albcans endocarditis with open heart surgery. $N$ Engl J Med 1961; 264: 907-10.

3 Dreyfus G, Serra F A, Jebara V A-Valve repair in acute endocarditis. Ann Thorac Surg 1990; 49: 706 -13.

4 Fleisher A, David I, Mogtader A, Huthinson JF- Mitral valvuloplasty and repair for infective endocarditis. $J$ Thorac Cardiovasc Surg 1987; 93: 311-5.

5 Gammage M D, Littler WA, Abrams L D - Conservative surgery of the mitral valve in bacterial endocarditis. Thorax 1984; 39: 868-71.

6 Chandraratina PA, Reagan R B, Imaizumi T Langevin E, Elkins RC - Infective endocarditis cured by resection of tricuspid valve vegetation. Ann Intern Med 1978; 89: $517-8$.

7 Edwards MB, Ratinatunga C P, Dore C J, Taylor K M Thirty-day mortality and long-term survival following surgery for prosthetic endocarditis: a study from UK heart valve registry. Eur J Cardiothorac Surg 1998; 14:156-64.

8 Vlessis A A, Khaki A, Grunkemeier G L, LI H H, StarrA - Risk, diagnosis and management of prosthetic valve endocarditis: a review. J Heart Valve Dis 1997; 6: 443-65.

9 Schuenemann S, Andreas S, Kreuzer H, Werner G S Complete morphologic and functional resolution of endocarditis of a Toronto stenless porcine bioprosthesis: a study by serial transesophageal echocardiography. J Am Soc Echocardiogr 1998; 11: $77-9$

10 Rensey E S \& Lytle B W - Repair of fungal aortic prosthetic valve endocarditis associated with periannular abscess. $\checkmark$ Heart Valve Dis 1998; 7: 235-9. 